УДК 316.354:351/354

НАМРУЕВА Людмила Васильевна - кандидат социологических наук, доцент; ведущий научный сотрудник отдела комплексного мониторинга и информационных технологий Калмыцкого научного центра Российской академии наук (358000, Россия, Республика Калмыкия, г. Элиста, ул. Илишкина, 8; Inamrueva@yandex.ru)

\title{
СЕЛЬСКИЕ ТЕРРИТОРИИ ЮГА РОССИИ: ДИНАМИКА ХОЗЯЙСТВЕННЫХ УКЛАДОВ
}

\begin{abstract}
Аннотация. В статье рассматриваются сельские уклады таких крупных аграрных российских субъектов, как Республика Калмыкия, Астраханская и Волгоградская обл., Ставропольский край. Значимость исследования заключается в том, что впервые проведен анализ хозяйственных укладов в гендерном разрезе на материале социологического исследования, проведенного летом-осенью 2018 г. в четырех указанных регионах. Массовый анкетный опрос позволил уточнить факторы, оказывающие влияние на сельскую многоукладность, специфичность сельского пространства, когда исчезают привычные формы хозяйствования и появляются новые очертания социальной структуры села. Результаты исследования позволили выявить наиболее важные проблемы сельских жителей: отсутствие рабочих мест, низкие финансовые возможности развития хозяйств, малодоступность государственной поддержки для крестьян, фермеров.
\end{abstract}

Ключевые слова: многоукладность, аграрная сфера, Республика Калмыкия, Астраханская область, Волгоградская область, Ставропольский край, сельское население, коллективные сельхозпредприятия, личные подсобные хозяйства, крестьянские фермерские хозяйства

$\mathrm{B}_{\mathrm{s}}^{\mathrm{v}}$ условиях, когда в начале 2020 г. катастрофически обрушились цены на нефть, угрожающе растет напряженность, связанная с появлением новых инфекций, когда рушится устоявшийся миропорядок, необходимо активизировать решение проблем продовольственной безопасности страны. Ее обеспечение зависит от эффективного развития различных хозяйственных укладов, которые, к сожалению, не в полной мере обеспечивают стабильное сельскохозяйственное производство, устойчивое развитие сельских территорий. В связи с этим требуются анализ и разработка рекомендаций по развитию многоукладности.

Российские социологи активно изучают проблемы сельских территорий - отток сельского населения, растущую безработицу, слабую социальную инфраструктуру, экономическую диспропорцию в развитии сельхозпредприятий, слабый демографический потенциал реализации программ сельской России. Однако практически отсутствуют исследования, в которых всесторонне, комплексно анализировались бы злободневные проблемы включения сельского населения нескольких регионов в рыночные отношения. Калмыцкие ученые пытаются рассмотреть эти вопросы на примере четырех южнороссийских регионов [Намруева 2019а; Намруева 2019б; Namrueva 2019; Nuskhaeva 2019]. Анализируемые крупные агропромышленные регионы Республика Калмыкия, Астраханская и Волгоградская обл., Ставропольский край - выполняют важную роль в обеспечении продовольственной независимости страны. Но, к сожалению, изучение использования женских трудовых ресурсов села не стало предметом научных исследований и управленческих действий. Наше исследование представляет собой попытку восполнить данный пробел.

Актуальность рассматриваемого исследования продиктована необходимостью комплексного анализа сельских реалий, позитивных/негативных резуль- 
татов проводимой аграрной политики, чтобы в дальнейшем разрабатывать рекомендации для органов власти по принятию управленческих решений для развития сельских территорий.

В статье использованы результаты предварительного этапа авторского социологического исследования, проведенного осенью 2018 г. в Республике Калмыкия, Астраханской и Волгоградской обл., Ставропольском крае. Выборочная совокупность составила 400 сельских жителей трудоспособного возраста, по 100 чел. в каждом регионе, поровну мужчин и женщин. Отметим, что подобное исследование по рассматриваемой проблематике осуществлено на Юге России впервые. В Калмыкии опрос проведен самим исследователем, в остальных регионах анкетирование осуществлено силами студентов, обучающихся по социологическим специальностям в вузах Волгограда, Астрахани, Ставрополя. Ввиду того что выборка недостаточна для рассмотрения в региональном распределении, автор анализирует полученный материал в гендерном разрезе.

Анализируемые южнороссийские регионы имеют полиэтничное население (в трех из них доминирует русское население, в Республике Калмыкия - титульное калмыцкое население) и различающуюся сельскохозяйственную производственную структуру. Несмотря на это, гендерные проблемы в сельской местности этих территорий особо не отличаются. Эти аграрные регионы характеризуются сокращением рабочих мест в аграрной отрасли, женских - в большей степени, массовым оттоком молодежи в города, активной трудовой миграцией сельских мужчин и женщин в поисках работы, средств существования, в т.ч. и за пределы своих регионов.

На Юге, как и на всей территории страны, возникают зоны запустения. Этот процесс, безусловно, связан с прекращением деятельности крупных сельскохозяйственных организаций. И.Н. Буздалов, академик РАН, дает неутешительную оценку состояния российских сел: «В деревне нет значимого социального слоя, способного радикально изменить ситуацию. Нет класса хозяев-профессионалов, владеющих современными достижениями науки и техники и располагающих всеми необходимыми для производительного труда материальными и культурно-бытовыми условиями. Наоборот, социально-трудовая сфера села подверглась беспрецедентному распаду. За последние 20 лет с карты страны исчезло около 17 тысяч сельских поселений, а большинство оставшихся обезлюдели» [Буздалов 2017].

Одной из главных причин сокращения сельского контингента стала ликвидация крупных сельхозпроизводителей - колхозов и совхозов. С начала 1990-х гг. на их базе появляются сельскохозяйственные производственные кооперативы (СПК), государственные предприятия, открытые и закрытые акционерные общества, товарищества и другие сельхозпредприятия. Коллективные формы хозяйств отличаются по размеру (от микропредприятий - до крупных) и моделям адаптации к рыночным условиям (потребительские и предпринимательские). В этот же период активное развитие получили семейные (частные) формы хозяйствования (КФХ, ЛПХ). Коллективный хозяйственный уклад перестал доминировать в сельской местности, его постепенно вытеснили те, что основаны на других способах хозяйствования и ином образе жизни.

В исследуемых регионах, как во многих российских субъектах, с 1990-х гг. активно происходит депопуляция малых и средних деревень. Вместе с тем на южнороссийском пространстве население концентрируется в крупных селах, в пригородных территориях. В результате трансформационных процессов изменились гендерные роли сельских жителей, установленные в советские времена. Ныне сельские женщины, став невостребованными в общественном 
производстве, заняты домашним хозяйством либо вынуждены покидать села с целью улучшения материального положения семьи.

В современной российской аграрной отрасли занято преимущественно мужское население, доля женщин составляет только 38\%. По мнению экспертов, «гендерный сдвиг обусловлен структурными трансформациями в агросекторе. После перехода к рынку более успешно развивалось земледелие (производство зерновых и подсолнечника), которое отличается высоким уровнем механизации и преимущественно мужской занятостью. Трудоемкое молочное животноводство с преобладанием женского труда не вышло из кризиса, что привело к сокращению занятости женщин в агросекторе» [Зубаревич 2017: 13].

В анализируемых регионах неравенство сельских женщин и мужчин имеется, но оно не критическое. В этой связи следует согласиться с экспертами, которые считают, что «развитие сельской местности в России обусловлено факторами, которые влияют на все население, без гендерных различий. Решение гендерных проблем в сельской местности не является приоритетом российских властей, социальные проблемы считаются более значимыми» [Зубаревич 2017: 14].

\section{Сельские хозяйственные уклады в южнороссийских регионах:}

\section{анализ исследования 2018 г.}

Аграрные преобразования 1990-х гг. заложили основы многоукладности в современном ее проявлении. Сформирована аграрная структура, в которую вошли как крупные, так и средние, и малые формы хозяйствования. Согласно толкованию С.И. Ожегова, под укладом понимается «устоявшийся порядок, сложившееся устройство жизни» ${ }^{1}$. О.П. Фадеева определяет сельские хозяйственные уклады как «специфику занятости и режим труда разных групп сельского населения - и опосредованно их образ жизни и особенности взаимодействия, в том числе вне экономической сферы» [Фадеева 2015: 26]. Автор разделяет позицию большинства ученых, которые выделяют в аграрном секторе три основных экономических уклада: сельскохозяйственные организации, крестьянские (фермерские) хозяйства и хозяйства населения [Фадеева 2015]. Далее рассмотрим состояние многоукладности, используя результаты авторского исследования в гендерном измерении.

Закрытый вопрос: «Занимаетесь ли Вы сами сельским хозяйством?» - позволил определить, какой уклад в настоящее время развит на селе. Полученные результаты показывают, что лишь небольшая доля мужчин и женщин (менее $10 \%$ ) устроены в сельскохозяйственном предприятии. Это свидетельствует о катастрофическом сокращении, ликвидации сельхозпредприятий в обследуемых регионах, т.е. коллективный уклад представлен в сельских реалиях, но далеко не в тех масштабах, которые были характерны для советских времен. Согласно разделяемому нами мнению О.В. Исаевой, недостатками коллективного уклада являются «усложненная система госрегистрации и налогообложения, отчуждение работников от результатов труда, низкая мотивация, сложности в организации управления и контроля» [Исаева 2019: 24].

Рассмотрим, как развит уклад частных хозяйств. Полученные в ходе анализируемого анкетного опроса данные свидетельствуют, что фермерский (индивидуально-предпринимательский) уклад почти в 2 раза чаще встречается на селе, нежели коллективный уклад. К его преимуществам отнесем семейный характер предприятия, основанный на принципах экономической свободы,

1 Ожегов С.И. 1988. Словарь русского языка (под ред. Н.Ю. Шведовой). 20-е изд., стереотип. М.: Русский язык. С. 677. 
высокую мотивацию труда, возможность получения господдержки по программам развития [Исаева 2019: 24]. Результаты в гендерном разрезе показывают, что в своем крестьянском фермерском хозяйстве в большей мере заняты мужчины (10,9\% по группе), чем женщины (6,6\%). Работают по найму у фермера чаще всего мужчины $(9,5 \%)$. Женщин, нанимающихся к фермерам, в 2 раза меньше $(4,8 \%)$. Суммирование двух вариантов ответов показывает, что $1 / 5$ опрошенных мужчин $(20,4 \%)$ работают в фермерском хозяйстве. Каждая девятая респондентка-селянка $(11,4 \%)$ занята в этом аграрном секторе. Можно констатировать, что мужчины гораздо чаще вовлечены в деятельность фермерских хозяйств, чем женщины.

Относительно уклада личных подсобных хозяйств заметим, что более 1/3 опрошенных $(35,7 \%)$ ведут или помогают вести личное подсобное хозяйство. Женщины $(37,5 \%)$ чуть более заняты на своем подворье, чем мужчины $(33,9 \%)$. Этому укладу в исследуемых регионах соответствуют такие виды сельскохозяйственной деятельности, как животноводство, выращивание фруктовых деревьев, овощей, пчеловодство. Преимущества ЛПХ заключаются в высокой мотивации труда, льготной системе налогообложения, отсутствии необходимости в госрегистрации [Исаева 2019: 24].

Издавна принято считать, что территория женщины - ее домашнее хозяйство, где она господствует. Прошлое столетие кардинально изменило положение сельской женщины, и в XXI в. социальная роль сельской женщины продолжает расширяться. О конкретных примерах новых ее ролей поведала Т.А. Жукова, ученый-социолог, ставшая фермером. В своем дневнике она правдиво описывает множество трудностей современного землевладельцатруженика. «Второй сезон при перегоне техники на “дальнее” поле возникают проблемы, если для выполнения работ необходимы несколько механизмов. Мне приходилось садиться за один из тракторов и, нарушая все законы и правила дорожного движения, ехать на поле». Автор дневника «активно помогала мужу на тракторах и самосвалах, обрабатывая почву, вывозя с поля урожай» [Жукова 2019: 159-160]. Администрация колледжа, где женщина хотела пройти курсы, чтобы получить водительское удостоверение категории «С» и удостоверение тракториста, не верила в ее решение, потому как стереотипы в обществе, выработавшиеся за века, еще весьма сильны.

Данные анализируемого опроса показывают, что, независимо от гендерной принадлежности, 1/10 опрошенных (10\%) признались, что занимались сельскохозяйственной деятельностью до развала Советского Союза. Каждый десятый респондент был задействован в аграрной отрасли в советском обществе, а потом сфера их занятости изменилась вследствие тех преобразований, которые пережила страна.

Из ответов более 1/4 выборочной совокупности следует, что ни они, ни члены их семей в настоящее время не занимаются сельскохозяйственными работами. Это также свидетельствует о том, что на селе отсутствие селообразующих предприятий заставило людей найти разные виды занятости, которые прежде не были характерны для деревни (сфера услуг, такси).

Обобщение результатов анкетирования позволяет констатировать, что лидирует уклад личных подсобных хозяйств $(35,7 \%)$. За ним следуют уклад крестьянских фермерских хозяйств (КФХ) (15\% по сумме двух ответов), замыкает тройку уклад сельскохозяйственных организаций (8\%). Таким образом, наш анкетный опрос показал, что малые хозяйства населения являются основой сельского социума южнороссийских регионов. Принято считать, что село живет, пока функционируют личные хозяйства [Намруева 2017: 88].

Известный исследователь села О.В. Нечипоренко отмечала в 2015 г., что 
«большинство сельского населения ориентировано на самообеспечение необходимыми продуктами натурального хозяйства, самозанято в личном подворье» [Нечипоренко 2015]. Однако заметим, что число ЛПХ постепенно снижается вследствие «высокой трудоемкости производства, полулегального характера деятельности, ограничения масштабов деятельности» [Исаева 2019: 24]. Результаты нашего опроса показали, что только 1/3 респондентов-селян заняты в своих хозяйствах. Если О.В. Нечипоренко писала в 2015 г., что «значительная часть населения адаптировалась к “шоковой терапии”, продемонстрировав бегство в дорыночные уклады» [Нечипоренко 2015], то в настоящее время, в 2020 г., и сельские жители постепенно усваивают нормы поведения и ценности, характерные для рыночного общества. Можно заключить, что и селяне шаг за шагом приспосабливаются к жизни в условиях рыночной экономики.

Проанализируем, какие факторы, по мнению респондентов, препятствует селянам держать домашнее подворье. Среди причин, мешающих респондентам вести домашнее подворье, в первую очередь названо отсутствие времени на его ведение (мнение 35,6\%), т.к. они полностью заняты на работе. Мнение мужчин и женщин совпадают. Ежегодно растет число селян, занятых несельскохозяйственными видами деятельности - торговлей, строительством, связью, сервисом, транспортом.

Менее 1/3 считают, что доходы с подворья не перекрывают расходы. Поэтому в селах активно открываются магазины, в т.ч. и супермаркеты, где можно приобрести необходимые продукты питания (молоко, хлеб, картофель и др.), которые прежде производились в частных хозяйствах. Зачастую в небольших магазинах селяне покупают продукты в долг, возвращая его после получения зарплаты, пенсии, других социальных пособий. Но порой долги так и остаются непогашенными, а магазины терпят большие убытки.

По мнению 1/4 опрошенных, подворье требует материальных затрат, а их у большинства селян нет, при этом затраты на ведение личного подворья не окупаются. Купить молоко, мясо в магазине легче и дешевле, чем содержать корову, готовить молочные продукты, стричь овец, заготавливать корма и т.д.

Следует заметить, что и мужчины, и женщины в одинаковой мере указали на тройку рассмотренных выше препятствий, которые не позволяют селянам заниматься личным подворьем.

Каждый шестой опрошенный отметил отсутствие желания заниматься сельскохозяйственным физическим трудом. Главная причина кроется в том, что в личном подворье сохранился примитивный ручной труд. Поэтому осталось лишь малое число тех, кто готов ухаживать за домашними животными, убирать хозяйственные помещения. Исходя из полученных данных, видно, что женщины в большей степени, чем мужчины, не хотят выполнять работу, требующую физических усилий. Бывшие селянки, получившие образование в вузе, колледже, привыкнув к городскому комфорту, не испытывают желания вернуться к тем трудовым занятиям, которые знакомы им с раннего детства.

Отметим, что селянки старшего возраста мечтают заниматься домашним подворьем, и их больше, нежели мужчин. Однако отсутствие здоровья не позволяет выполнять тяжелую работу по хозяйству. Это косвенным образом показывает, что на селе остались пожилые люди, которые по привычке готовы работать, но, увы, состояние их здоровья не позволяет им это делать.

Мужчины чаще женщин считают, что отсутствие возможности получить кредит на развитие хозяйства препятствует ведению личного хозяйства. «По мнению экспертов, инвестиции, выделяемые на аграрную отрасль, идут в банки и крупные корпорации. 20 сельскохозяйственных олигархов получают 95\% господдержки. Остальные 5\% делят между собой более 52 тыс. сельско- 
хозяйственных организаций (бывшие колхозы и совхозы), 27 тыс. микропредприятий и более 216 тыс. КФХ. В этой ситуации особенно сложно фермерам, поэтому они не выдерживают конкуренции и вынуждены уходить, в основном в ЛПХ. Выделяемые правительством гранты фермерам настолько незначительны, что вряд ли помогают развивать хозяйство. В 2017 г. получили кредиты на развитие хозяйства всего лишь 10\% КФХ» [Муханова 2018: 129].

Вследствие имеющихся диспропорций в инвестировании сельхозпроизводителей владельцы личных подворий не имели возможности получить необходимую финансовую помощь. К счастью, в 2019 г. появилась новая форма государственной поддержки - гранты «Агростартап» в помощь тем, кто планирует организовать фермерское хозяйство. Этот грант может получить и владелец личного подсобного хозяйства, но с условием, что в течение месяца после получения данной поддержки грантодержатель зарегистрирует свое КФХ в налоговой службе. Максимальный размер субсидии на создание и развитие КФХ - не более 1 млн руб., а на формирование неделимого фонда сельскохозяйственного потребительского кооператива, членом которого является заявитель, за счет средств субсидии (от 25 до 50\%) - 1,5 млн руб. на одного получателя 1 .

Из опыта наших многолетних исследований явствует, что калмыцкие респонденты указывают на такую актуальнейшую проблему, как отсутствие воды, водопровода. Для республики, где огромные территории отнесены к засушливым, нерешенность проблемы с водой представляет основной барьер в развитии аграрной отрасли, сельских поселений.

Рассмотренные сельские хозяйственные уклады (сельхозпредприятия, ЛПХ, фермерские хозяйства) характеризуют не только устоявшийся порядок привычной сельской жизни, но и кардинальные изменения в сельскохозяйственной деятельности. Уклады, трансформируясь в последние три десятилетия, преобразовывают современную южнороссийскую деревню, изменяют сельское население, его взгляды, установки, поведение. Формирование гибкой хозяйственноукладной структуры позволяет современному селу выжить в эпоху постоянных перемен, в условиях кризисов и реформ.

Статья подготовлена в рамках государственного задания КалмНЦ РАН «Развитие сельских территорий Юга России: комплексный социально-экономический и экологический мониторине» (рег. № НИОКТР АААА-А19-1190111490037-8).

\section{Список литературы}

Буздалов И.Н. 2017. Главный путь преодоления системного кризиса и обретения Россией статуса мировой продовольственной державы. Экспортный потенциал АПК России: состояние и перспективы. М.: ВИАПИ им. А.А. Никонова. С. 4-9.

Жукова Т.А. 2019. Из дневника фермера. - Устойчивое развитие сельских территорий. Стабильная социально-экономическая структура села как предпосылка устойчивого развития сельских территорий: сборник статей (отв. за вып. А.А. Хагуров). Краснодар: КубГАУ. С. 125-174.

Зубаревич Н. 2017. Развитие сельских территорий России, социальные и гендерные проблемы. - Международный сельскохозяйственный журнал. № 2. C. 12-14.

Исаева О.В. 2019. Многоукладность сельского хозяйства России: современ-

1 Сангаджиева В. 2020. «Агростартап» поможет стать фермером. - Хальмг унн. 22 янв. C. 3 . 
ные тенденции и перспективы развития. - Экономика и экология территориальных образований. Т. 3. № 3. С. 20-30.

Муханова М.Н. 2018. Сельское население в структурах неформального сектора на рынке труда АПК. - Власть. Т. 26. № 5. С. 125-132.

Намруева Л.В. 2017. Современное село Калмыкии: социологический срез: монография. Элиста: КалмНЦ РАН. 180 с.

Намруева Л.В. 2019а. Взаимодействие коллективного и семейного укладов в южнороссийских селах (по материалам исследования 2018 г.). - Logos et Praxis. № 2. С. 134-141.

Намруева Л.В. 2019б. Мозаика современной жизни сельского населения Калмыкии (по итогам качественных исследований 2019 г.). - Oriental Studies. № 5(45). С. 938-944. Доступ: https://doi.org/10.22162/2619-0990-2019-5-938944 (проверено 26.08.2020).

Нечипоренко О.В. 2015. Современное развитие сельских территорий в России: глобальные тренды и локальные инновации. - Социальные проблемы российского села и аграрных отношений: материалы международной научной конференции. Седьмые Санкт-Петербургские социологические чтения. 16-18 апреля 2015 г. СПб: СПбГАУ. С. 300-307.

Фадеева О.П. 2015. Сельские сообщества и хозяйственные уклады: от выживания к развитию (под ред. З.И. Калугиной). Новосибирск: ИЭОПП СО РАН. $264 \mathrm{c}$.

Namrueva L. 2019. Transformation of Collective Patterns in Southern Russian Villages in Early $21^{\text {st }}$ Century. - European Proceedings of Social and Behavioural Sciences. P. 2399-2406.

Nuskhaeva B.B. 2019. Economic Situation of the Rural Population in the Southern Regions of Russia. - European Proceedings of Social \& Behavioural Sciences. P. 25032509.

NAMRUEVA Ludmila Vasil'evna, Cand.Sci. (Soc.), Associate Professor; Leading Researcher of the Department for Complex Monitoring and Information Technologies, Kalmyk Scientific Center of the Russian Academy of Sciences (8 Ilishkina St, Elista, Republic of Kalmykia, Russia, 358000; Inamrueva@yandex.ru)

\title{
RURAL TERRITORIES OF THE RUSSIA'S SOUTH: DYNAMICS OF ECONOMIC STRUCTURES
}

\begin{abstract}
The article deals with the main problems of rural life in such agrarian Russian subjects, as the Republic of Kalmykia, the Astrakhan and Volgograd Regions, the Stavropol Territory. The significance of the study lies in the fact that for the first time an analysis of economic patterns in the gender context was carried out on the base of a sociological study conducted in the summer-autumn 2018 in these four regions. A mass questionnaire survey allowed us to clarify the factors that influence rural diversity, the specificity of rural space, when the usual forms of management disappear and new outlines of the social structure of the village appear. At present, the situation of private farms has certainly changed compared to early 1990s. The author of the article determines the marketability of family farms, entrepreneurial activity of smallholders, and the presence/ lack of motivation of the rural population to the maintenance of peasant farms.

Diversity, types of employment in various fields, and income levels of the rural population determine the main changes in rural life. The results of the study reveal the most important problems of rural residents, such as lack of jobs, low financial opportunities for farm development and low availability of state support for farmers.
\end{abstract}

Keywords: multiculturality, agricultural sphere, Republic of Kalmykia, Astrakhan Region, Volgograd Region, Stavropol Territory, rural population, collective agricultural enterprises, personal subsidiary farms, peasant farms 